\title{
Overview and evaluation of the value of fine needle aspiration cytology in determining the histogenesis of liver nodules: 14 years of experience at Hannover Medical School
}

\author{
B. SOUDAH ${ }^{1}$, A. SCHIRAKOWSKI ${ }^{1}$, M. GEBEL ${ }^{2}$, A. POTTHOFF ${ }^{2}$, P. BRAUBACH ${ }^{1}$, \\ J. SCHLUE ${ }^{1}$, T. KRECH ${ }^{1}$, M.E. DÄMMRICH ${ }^{1}$, H.H. KREIPE ${ }^{1}$ and M. ABBAS ${ }^{1}$ \\ ${ }^{1}$ Institute of Pathology and ${ }^{2}$ Department of Gastroenterology, Hepatology and Endocrinology, \\ Hannover Medical School, D-30625 Hannover, Germany
}

Received June 30, 2014; Accepted August 20, 2014

DOI: 10.3892/or.2014.3554

\begin{abstract}
Fine needle aspiration (FNA) is a sensitive and specific method (95\%), often helpful in characterizing suspected liver lesions. It is appropriate to distinguish between primary and secondary liver neoplasia. Moreover, in most cases, the use of cell block preparations of small specimens allows immunocytochemical evaluation to determine the nature of the primary tumour. In a retrospective study at Hannover Medical School (MHH) from 1998 to 2012 (14 years), 4,136 sonographically guided FNAs were performed. The patients provided consent and the study protocol was approved by the local ethics committee. There were $39.6 \%$ malignant and $57.5 \%$ benign lesions in the liver, while $2.8 \%$ of the cases were undetermined. FNA was non-representative in $1.1 \%$ of the cases. The diagnostic utility of highly differentiated hepatocellular carcinoma (HCC; G1) remains difficult; cell bridges with cell atypia are pathognomonic for diagnosis. Ancillary techniques and immunocytochemical investigations will increase the sensitivity and specificity, particularly by using the cell block technique.
\end{abstract}

\section{Introduction}

Fine needle aspiration cytology (FNAC) has great value in determining the histogenesis of suspected liver nodules (1-3). The main role of diagnostic cytology is the differentiation between primary and secondary liver tumours as well as to confirm malignancy by exclusion of inflammatory nodules including simple cysts and granulomatous nodules such as tuberculosis or sarcoidosis (4-6). The only contraindication of FNAC is improper coagulation by a low number of platelets (7).

FNAC has the advantage of being a non-aggressive method with a low risk for complications $(2,8)$. Successful FNAC

Correspondence to: Dr B. Soudah, Institute of Pathology, Hannover Medical School, Carl-Neuberg Street 1, D-30625 Hannover, Germany E-mail: soudah.bisharah@mh-hannover.de

Key words: overview study, FNAC, liver nodules provides cells and tissues that are extremely useful for the diagnosis conducted by biopsy specimens (9).

The sensitivity and specificity of FNAC from liver nodules in the retrospective study was $\sim 90 \%$ after examining more than 4,000 cases at the Institute of Pathology at Hannover Medical School (MHH).

The aim of this retrospective study was to detect the validity of FNAC in determining the malignancy of liver nodules and to differentiate between primary tumours and metastasis.

Overview of the aetiology of liver nodules. The aetiology of liver nodules vary and two main types, solid tumours and cystic liver lesions, are observed. Solid tumours include i) tumours with abnormal contrast-enhanced ultrasound (CEUS); ii) malignant tumours; iii) metastasis in the liver by the presence of primary tumours in other organs; and iv) tumours after adjuvant therapy to detect vitality and regression. Cystic liver lesions include: i) histogenesis (abscess, simple cyst, haemorrhage); ii) cystic degeneration in a malignant tumour (mucin); and iii) parasites (hydatid cyst), bacteria, hyphae or actinomycosis.

Contraindication of FNAC of the liver includes: i) improper coagulation/coagulopathy (quick $<50 \%$, PTT $>50 \%$, thrombocytes $<50.000 / \mu \mathrm{l}$; ii) therapy with heparin, coumarin or aspirin; iii) ascitis; iv) lack of consent from the patient; v) eating a meal before the procedure; and vi) absence of family or medical history.

Cytological appearance of normal liver cells. The cytological appearance of normal cells in smear slides are as follows. Normal liver cells are polygonal cells either isolated or in groups of cells (6-8 cells). Focal lipofuscin is detected in older patients. The cytoplasm is distinct, wide and stained red in haematoxylin and eosin (H\&E) preparation by the presence of many mitochondria. The nucleus is central and round. The chromatin is finely clumped but regular. The nucleolus is central and stained red in H\&E. In $\sim 25 \%$ of liver cells, there are two nuclei. Nuclear inclusions are found in liver cells of older patients or patients with diabetes mellitus (Fig. 1A).

Bile duct cells are cubical or columnar cells, isolated or in groups. The cytoplasm is narrow and stained bright-red in 


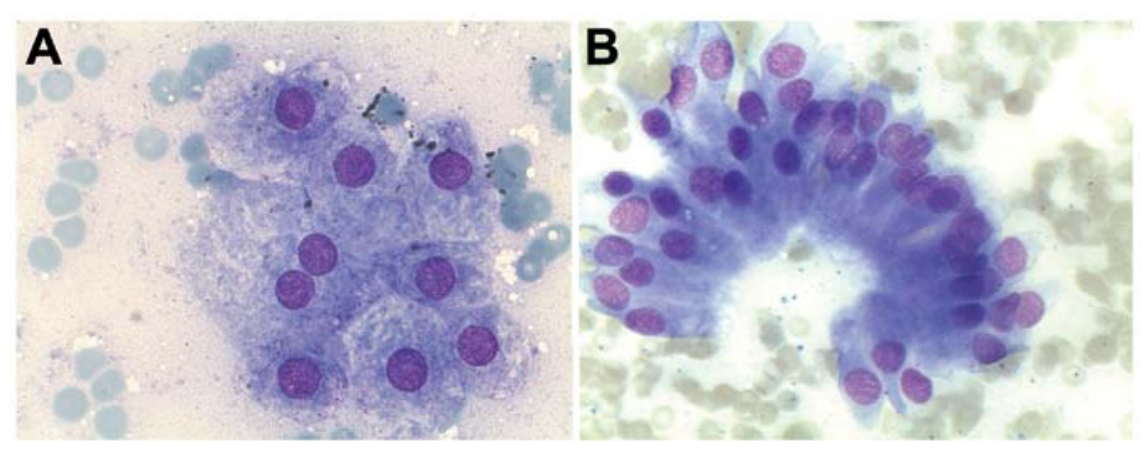

Figure 1. (A) Normal liver cells (Giemsa staining; magnification, x180:1). (B) Normal bile duct cells.
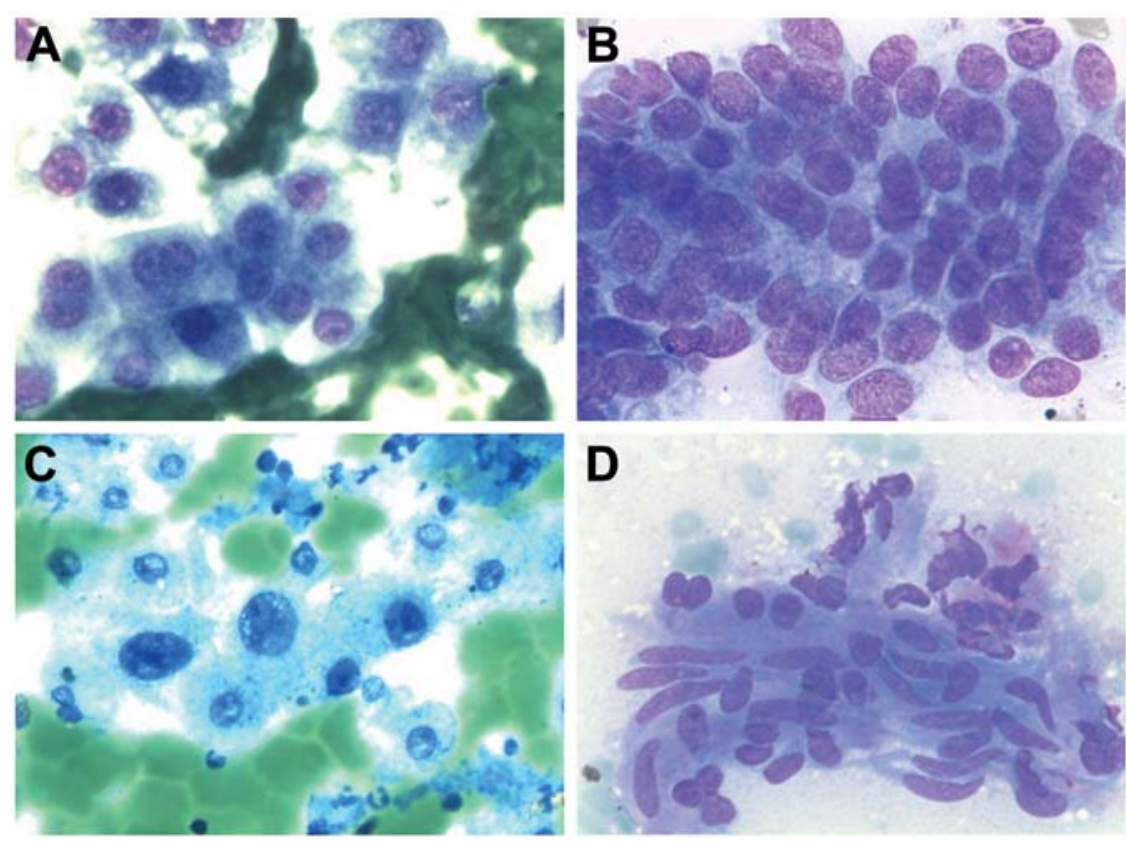

Figure 2. Liver cirrhosis: epithelial cell regeneration and hyperplasia, bile duct and endothelial cells (Giemsa stain; magnification, x140:1).

H\&E smears (Fig. 1B). The nucleus is in the periphery and oval. The chromatin is fine and granular. The nucleolus is indistinct. The endothelial cells of sinusoids are arranged in groups of spindle cells. The cytoplasm is narrow. The nucleus is oval and the chromatin is fine and granular. Kupffer cells are rare in FNAC. They lie superficially in the sinusoidal side of the liver cells. The cytoplasm is narrow with vacuoles. The nucleus is oval with fine-granular chromatin.

In benign, non-neoplastic nodular lesions of the liver in FNAC, the liver cells show cytoplasmic changes as well as the accumulation of metabolic products can be detected in metabolic intolerance or toxic disturbances as well as by enzymatic inborn diseases. For example, the detection of fat globules enhances the diagnosis of fatty liver; the detection of iron in the cytoplasm enhances the diagnosis of siderosis or hemochromatosis as well as possible after blood-transfusion. The detection of accumulated copper in the cytoplasm may be indicative of Wilson syndrome.

FNAC is of limited value to detect the aetiology of liver cirrhosis, yet of value to document the presence of fibrosis (Fig. 2A-D). The role of special pigments is important in detecting accumulated materials: iron (Perls' Prussian blue) appears as intracytoplasmic dark blue, lipofuscin (H\&E) appears as perinuclear yellow brown pigment, melanin appears as dark blue to black pigment, and bile pigment appears as dark green or black.

Fatty liver is due to accumulation of triglycerides. Cytoplasmic vacuoles are observed. The aetiology is primarily an error in the metabolism of fat, for example hypertriglyceridemia, a high-level of cholesterol and triglycerides due to alcohol, diabetes mellitus, hypoxia or bad nutrition. In the cytoplasm, fine to coarse vacuoles can be noted that push the nucleus to the periphery. It is not a special indication for FNA as it can be diagnosed either by cytology or by biopsy.

Cholestasis is due to intracellular accumulation of bilirubin and appears as red green pigmentation either in the liver cells or in the sinusoids. This is caused by bile duct stones, metabolic inborn error, malignant tumours (obstructive cholestasis), or by infection as well as medications. The aetiological detection of different types of cholestasis is cytologically impossible.

Inflammation of the liver leads to unspecific cellular changes. Therefore, FNAC is helpful in detecting the aetiology yet not in cases of viral hepatitis. In abscesses, there are 
Table I. FNAC of the liver.

\begin{tabular}{lr}
\hline Diagnosis & No. $(\%)$ \\
\hline Benign lesion & $2,353(56.8)$ \\
Malignant lesion & $1,620(39.1)$ \\
Unclear/not defined & $114(2.7)$ \\
Not sufficient to make a diagnosis & $49(1.1)$ \\
Total & 4,136
\end{tabular}

FNAC, fine needle aspiration cytology.

Table II. Malignant liver lesions in the FNAC.

\begin{tabular}{lc}
\hline Diagnosis & No. $(\%)$ \\
\hline Liver cell carcinoma & $648(40.0)$ \\
Bile duct carcinoma & $170(10.4)$ \\
Metastasis & $802(49.5)$ \\
Total & 1,620
\end{tabular}

FNAC, fine needle aspiration cytology.

neutrophils, macrophages, necrosis or apoptosis and liver cells with regenerative changes. In granuloma, this is an incidental diagnosis in FNAC, particularly if thick needles are used. There is cellular accumulation of macrophages, lymphocytes and plasma cells. In cysts, there is a detection of a cavity in the liver. The cause of cystic changes is congenital and simple (Fig. 8), echinococcus and secondary changes in the tumour. In congenital and simple cysts, there are macrophages, fluid in the background and metaplasia in the cells, bile duct cells, possibly mucus in cases of cystic mucoid tumour or parasitic cysts. In echinococcosis, dirty background, inflammatory cells, spikes and PAS-positive material are noted. In secondary cysts, due to degeneration of tumours they appear cytologically with dirty background and atypical cells. In liver cirrhosis, FNAC is of no value in detecting the aetiology of cirrhosis but may be of value in the differentiation between regenerative nodules and early phase of well-differentiated liver cell carcinoma. There are many cells in groups or rosettes. The cells show regenerative changes with nuclear pleomorphism and anisokaryosis. Many cells have two nucleoli. The chromatin is regular. The cells also show a broad cytoplasm and distinct cell membrane. Cholestasis appears in the sinusoids or in the liver cells. In toxic aetiology, the cells show many fat droplets. In the background, there are many stroma or endothelial cells. Bile duct cells may also present either in groups or in rosettes. For neoplastic liver lesions (WHO, 2010) refer to Table V and for secondary tumours: lung, breast, pancreas, colon and stomach refer to Table III.

\section{Cytological characteristics of benign liver cell tumours}

Liver cell adenoma. Here there is no cirrhosis. There are no parenchymatous changes in the surrounding tissue. Ultrasonography appears as cystic degeneration in the
Table III. Primary tumours of the liver metastasis.

\begin{tabular}{lrr}
\hline Known primary tumour of liver metastasis & No. $(\%)$ \\
\hline Colon/rectum & $188(27.6)$ \\
Pancreas & $113(16.5)$ \\
Breast (Fig. 10B) & $67(9.8)$ \\
Neuroendocrine tumours (NET) & $77(11.3)$ \\
CUP (carcinoma of unknown primary) & $66 \quad(9.6)$ \\
Lung (non-small cell carcinoma) & $30(4.4)$ \\
Stomach and NHL (each) & $19(2.8)$ \\
Sarcoma (Fig. 3D) and kidney (each) & $15(2.2)$ \\
Lung (small cell carcinoma) & $12 \quad(1.7)$ \\
Prostate & $9 \quad(1.3)$ \\
Urinary bladder & 7 & $(0.8)$ \\
Gall bladder, oesophagus, malignant melanoma & 6 & $(0.8)$ \\
(Fig. 8B), thyroid gland (each) & & \\
Vagina/cervix, pharynx, testis (each) & $3 \quad(0.4)$ \\
Plasmacytoma and ovary (each) & $2 \quad(0.3)$ \\
AML, salivary gland, adrenal gland and & $1 \quad(0.1)$ \\
undifferentiated carcinoma (each) & & \\
Total & 681 & \\
\hline
\end{tabular}

Total number, $802 ; 121$ of unknown primary in the patient's history.

Table IV. Immunocytochemical markers (14).

\begin{tabular}{|c|c|}
\hline Types of cancer & Markers \\
\hline $\mathrm{HCC}$ & $\begin{array}{l}\text { Hep-par-1, CEA, glypican-3, } \\
\text { glutamine synthetase, HSP-70, } \\
\beta \text {-catenin, arginase-1, CD-10, } \\
\text { AFP, CK7/CK20 }\end{array}$ \\
\hline $\mathrm{CCC}$ & CK7/CK19, CK7/CK20 \\
\hline NET & $\begin{array}{l}\text { Chromogranin, synaptophysin } \\
\text { NSE, CD56 }\end{array}$ \\
\hline Pancreas & CK7/CK20 \\
\hline Colon/rectum & CK20, CDX-2 \\
\hline Haemangioendothelioma & CD31, factor VIII \\
\hline M. lymphoma & CD45, CD20 and KL-1 (-ve) \\
\hline
\end{tabular}

tumour. FNAC is contraindicated due to haemorrhagic risk. Cytologically, there are monomorphic cells arranged in pseudoacinar formations. The cells show minimal nuclear atypia with granular chromatin and a large nucleolus. The cytoplasm is light and distinct with vacuoles. In the background of the smear there is excessive necrosis, blood, macrophages with bile pigment and inflammatory cells. Liver cell adenomas are classified into 4 groups according to genetic changes (Bordeaux Classification) (10,11): i) liver cell adenoma with HNF1 $\alpha$ inactivation; ii) liver cell adenoma with $\beta$-catenin activation (high risk of progression to carcinoma); iii) liver cell adenoma with inflammatory changes; and iv) liver cell adenoma, not otherwise specified. 
Table V. Liver nodules (WHO, 2010).

\begin{tabular}{lll}
\hline Structure & \multicolumn{1}{c}{ Benign lesions } & \multicolumn{1}{c}{ Malignant lesions } \\
\hline Liver cells & $\begin{array}{l}\text { Liver cell adenoma, nodular regenerative hyperplasia, } \\
\text { focal nodular hyperplasia and dysplastic nodules }\end{array}$ & $\begin{array}{l}\text { Liver cell carcinoma: micro/macronodular, } \\
\text { fibrolamellar, acinar or adenoid, clear cells, } \\
\text { solid subtypes } \\
\text { Bile duct cells }\end{array}$ \\
$\begin{array}{l}\text { Endothelial cells } \\
\text { Others }\end{array}$ & $\begin{array}{l}\text { Simple cysts, bile duct adenoma, bile duct cystadenoma } \\
\text { Cavernous haemangioma }\end{array}$ & $\begin{array}{l}\text { Bile duct carcinoma and cystadenocarcinoma } \\
\text { HCC-CCC, hepatoblastoma }\end{array}$ \\
\hline
\end{tabular}
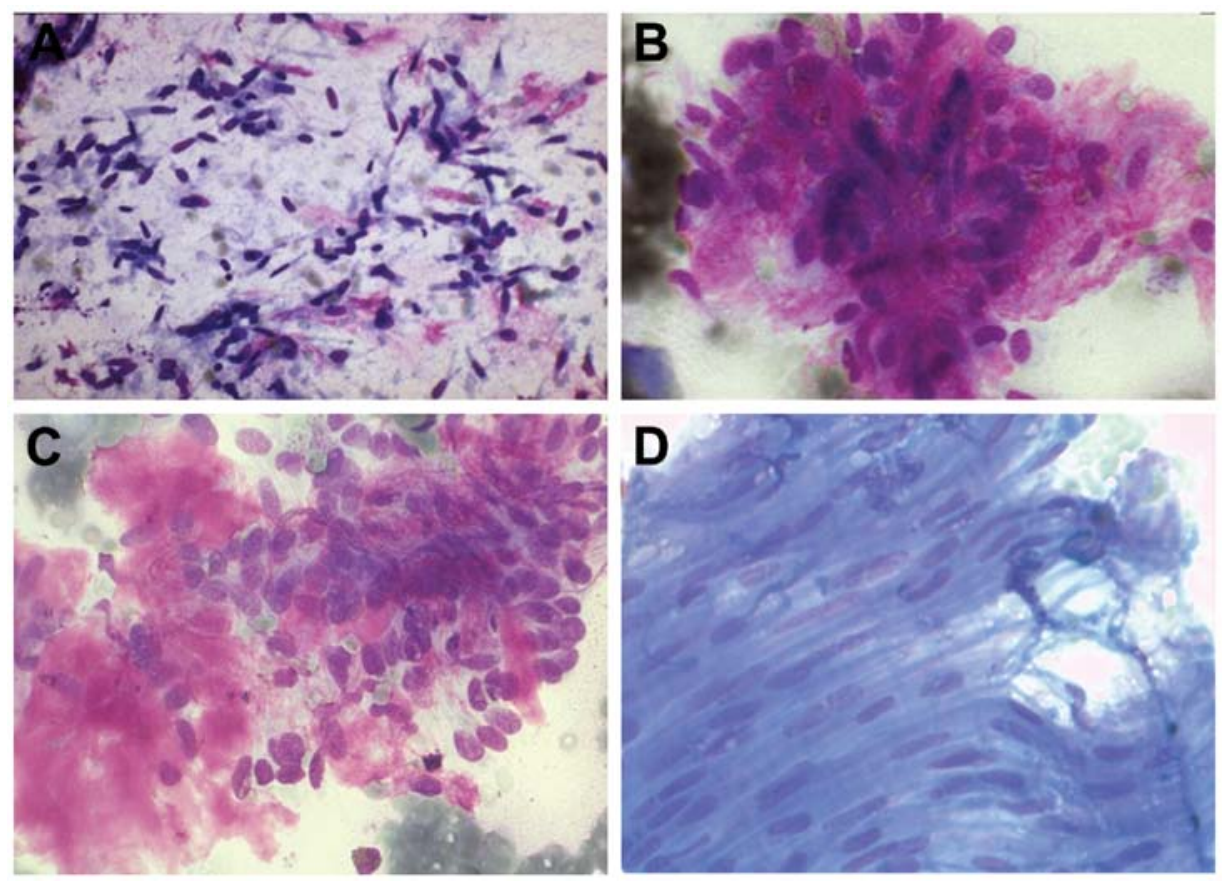

Figure 3. (A and B) Cavernosis haemangioma. (C) Haemangiosarcoma, (D) Giemsa stain (GIST; magnification, x140:1).

Focal nodular hyperplasia $(F N H)$. Focal nodular hyperplasia is cytologically impossible.

Cavernous haemangioma of the liver. Cavernous haemangioma is an incidental diagnosis due to the use of thick needles in FNAC or in autopsy specimens. Cytologically (Fig. 3A-C), there is a background with blood and endothelial cells. Many liver cells are also present. The diagnosis should be made concomitantly with radiologic diagnosis.

Liver cell dysplasia. Liver cells show nuclear pleomorphism, and atypia is common in cases with liver cell cirrhosis. Cases (5-40\%) with liver cell cirrhosis are complicated by liver cell dysplasia and carcinomas. Investigation with FISH is useful to detect aneuploidy which may be a criterion to detect hepatocellular carcinoma (HCC) (12).

Cytological features of malignant liver cell tumours [grading according to Edmondson and Steiner (13)]

Hepatocellular carcinoma. HCC presents widely in Asia and Africa in comparison with Europe. It is associated with hepatitis $\mathrm{B}$ and $\mathrm{C}$ and is more common in men than in women $(4: 1)$. Cases $(90 \%)$ are preceded by liver cirrhosis. Different grades of liver cell carcinoma have different cytological features. In HCC (G1), the smears show many cells and a clean background. The cells are arranged in rosettes. The atypical cells are smaller than normal cells. The nuclei are round with a prominent nucleolus. The cytoplasm is stained light red with a disturbed nuclear/cytoplasmic ratio. In HCC, the fibrolamellar type appears cytologically as abnormal strands of liver cells with fragmentation of the stroma and cytoplasm stained red due to mitochondria. The diagnostic feature is the formation of bridges of endothelial cells (Fig. 4). In HCC (G2), the smears are rich with abnormal strands of cells. The liver cells show atypical changes such as increased nuclear/ cytoplasmic ratio. The nucleus appears large with clumped chromatin and irregular nuclear membrane. The nucleolus is large and prominent. The cytoplasm is narrow and irregular. Some show mitotic images. Clear cell type shows positive glycogen with PAS staining (Fig. 5). In HCC (G3), the former criteria of atypical changes are in the liver cells with aggressive fragmentation of the stroma as well as formation of bridges of endothelial cells. Irregular cell and nuclear membranes are present. Necrotic changes in the background (Fig. 6) are noted. In HCC $(\mathrm{G} 4)$, there is prominence of the atypical changes in the liver cells, appearing not only in groups yet also in 


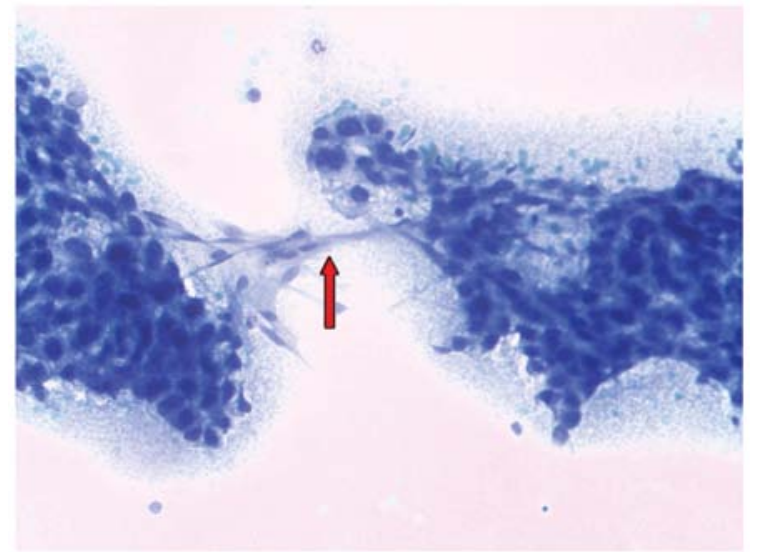

Figure 4. HCC G1 with endothelial bridges (Giemsa stain; magnification, $\mathrm{x} 140: 1)$.

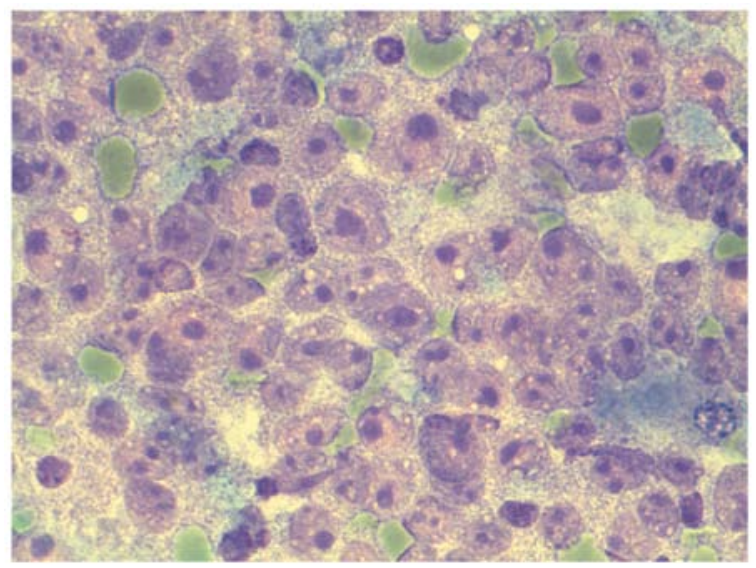

Figure 5. HCC G2, intermediate atypical changes (Giemsa stain; magnification, $\mathrm{x} 180: 1)$

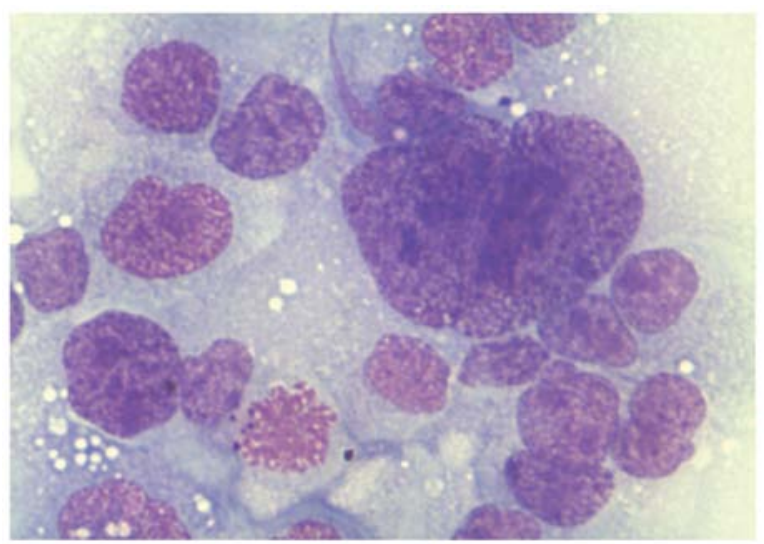

Figure 6. HCC G3, high grade atypical cellular changes (Giemsa stain; magnification, x180:1).

separate cells. Smears show a dirty background and necrosis. Indistinct cells and cytoplasmic membranes are present. The prominence of the nucleolus is always present. In the clear cell type, the neoplastic liver cells show clear cytoplasm with fine vacuoles. Cytologically, it is difficult to differentiate between this subtype and metastasis from adrenal gland carcinoma or clear cell carcinoma of the kidney.
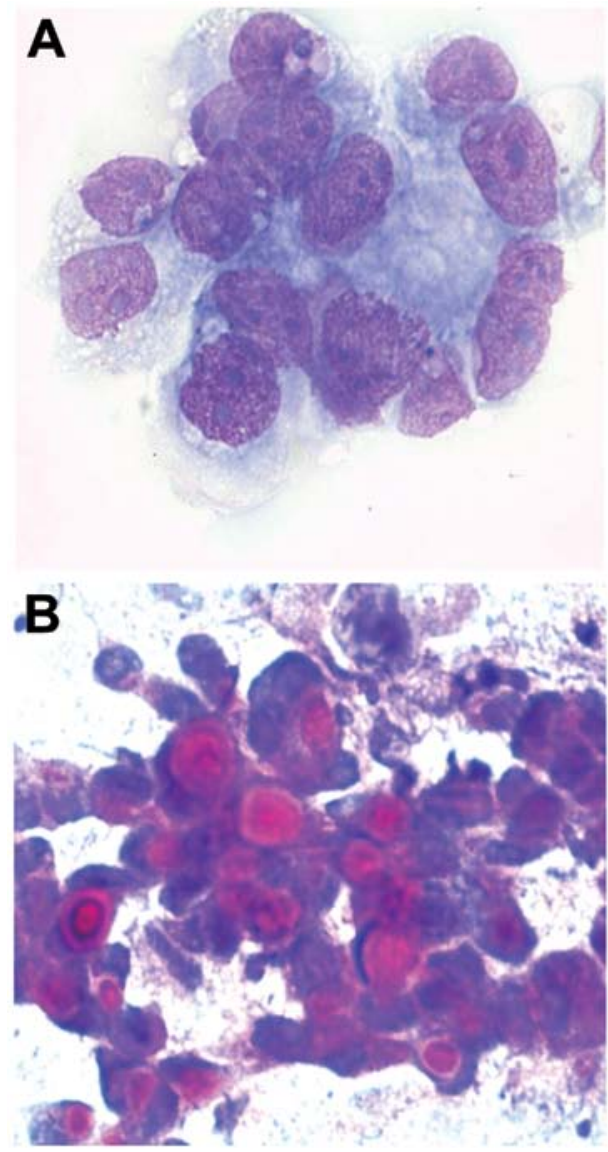

Figure 7. Bile duct cells (CCC) with hyperchromasia and pleomorphism. (A) Giemsa stain; (B) PAS stain, positive; magnification, x180:1.

Bile duct carcinoma. In bile duct carcinoma, due to marked desmoplasia that accompanies adenocarcinoma of the bile tract, the smears show a small number of cells. The cells are arranged in groups or in glands. They show peripheral nuclei with polymorphic changes. The cytoplasm is lightly stained with vacuoles. PAS staining shows positive vacuoles (Fig. 7).

Hepatoblastoma. In hepatoblastoma, the smears are rich with cells and necrotic debris. The cytoplasm is narrow. The cells show indistinct cell and nuclear membranes. There are many prominent nucleoli with atypical mitosis and increased nuclear/ cytoplasmic ratio. Stromal cells and squamous metaplasia are present. Extramedullary haematopoiesis is sometimes present (Fig. 8A).

Metastasis. In regards to metastasis in the liver, cytomorphologic, immunohistochemical and clinical data are important for the diagnosis. FNAC is a helpful method in the differentiation between primary tumours and metastasis (Figs. 8B and 10B). For example, i) in colorectal carcinoma, groups of cells with necrosis and inflammatory cells are observed. Cubical cells with atypical changes (Fig. 9A) are noted. ii) In squamous cell carcinoma, there are large cells with a wide cytoplasm and tail. iii) In neuroendocrine carcinoma, there are rosettes of cells with monomorphism (Fig. 10A); and iv) in lymphoma, isolated cells with little cytoplasm and pleomorphism are observed. The immunocytochemical (IH) (Table IV) or fluorescence in situ hybridisation (FISH) investigation of the 


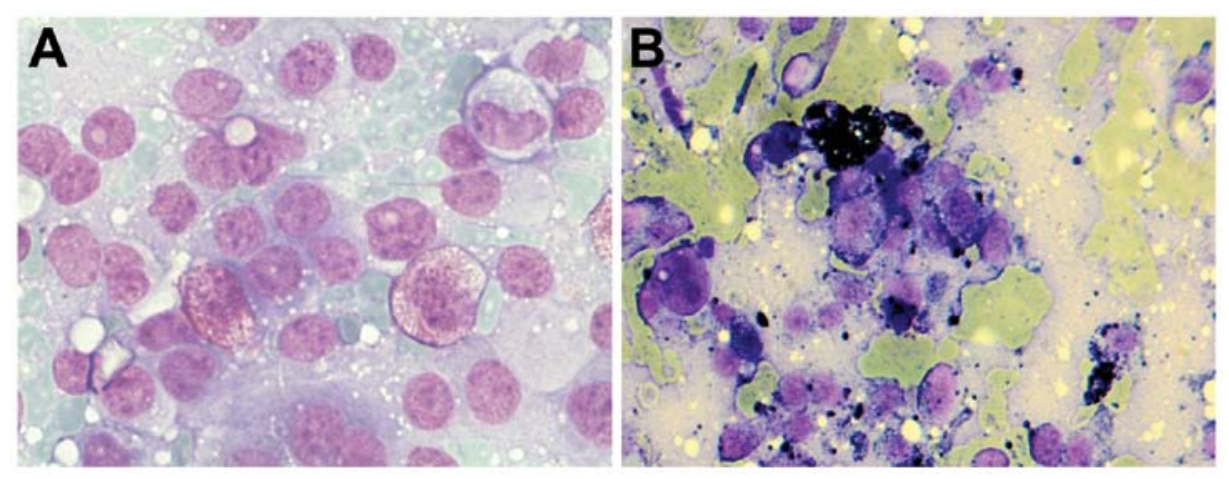

Figure 8. (A) Hepatoblastoma (Giemsa stain; magnification, x180:1). (B) Malignant melanoma.

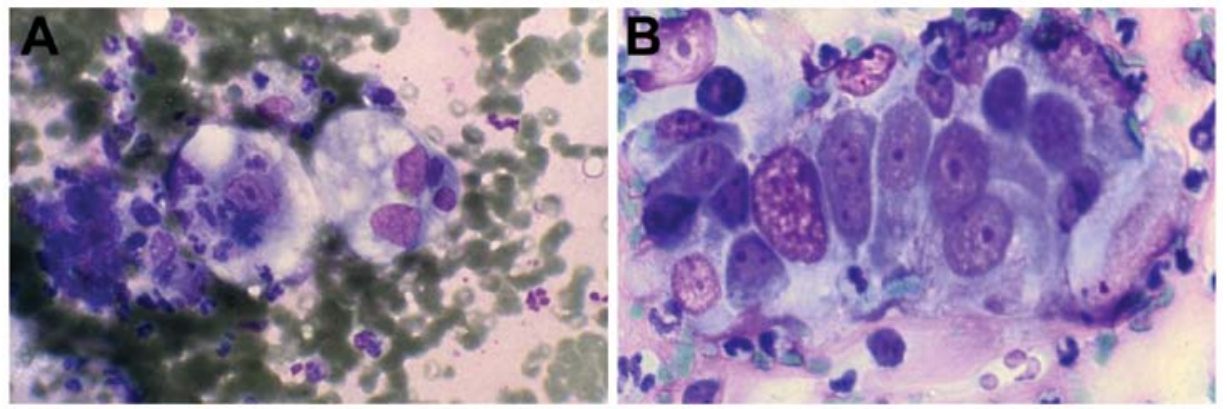

Figure 9. (A) Cells of colon carcinoma (metastasis). (B) Cells of pancreas carcinoma (metastasis).
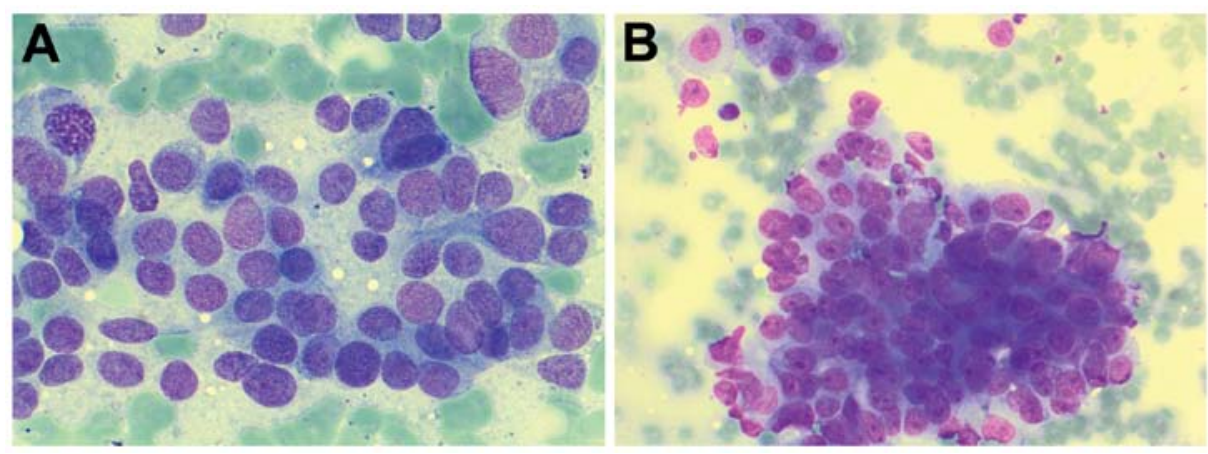

Figure 10. (A) Neuroendocrine tumour (NET). (B) Cells of breast cancer (metastasis) (Giemsa stain; magnification, x180:1).

smears is helpful yet due to few cells, may be difficult to use. To enhance the use of ancillary techniques such as IH or FISH, it is recommended to process the samples as a cell block. Some metastases, for example from pancreas adenocarcinoma (Fig. 9B), are difficult to diagnose accurately even after use of ancillary techniques. This is also the case in the equivalent biopsy (Fig. 9B). Alkaline phosphatase is positive in all cases of HCC and negative in all cases of metastasis.

\section{Materials and methods}

All samples were processed in our institute and stained with Giemsa and PAS stains as conventional methods at the Institute of Pathology at the Hannover Medical School (MHH). They were compared with the histological specimens that were processed at the same institute. The patients were informed that probable studies may be performed and they provided consent. The retrospective analysis of the present study was approved by the local ethics committee.

\section{Results}

Cytological examination of 4,136 (FNAC) specimens from 1998 to 2012 found that $39.6 \%$ of the cases were malignant, $57.5 \%$ were benign and $2.8 \%$ had unclear cytology. Approximately $1.1 \%$ of the specimens were not sufficient for diagnosis (Table I). In the malignant cases, $40 \%$ were liver cell carcinoma, $10.4 \%$ were bile duct carcinoma (CCC) and $\sim 48.5 \%$ were metastasis (Table III).

\section{Discussion}

FNAC is the method of choice to detect the aetiology of the majority of abnormal nodules of the liver. It is a sensitive 
and non-aggressive, cost effective and rapid method and with proper processing and experience, the nodules can be easily diagnosed. For unclear tumours, it is preferable to process samples by cell block techniques to enhance the use of ancillary techniques such as immunocytochemistry or FISH.

In this retrospective study (1998-2012), 4,136 FNAC were carried out from patients at the $\mathrm{MHH}$, and diagnosed at the Institute of Pathology. The majority $(97.1 \%)$ were correctly diagnosed in comparison to the corresponding histopathology. The remaining cases could not be accurately diagnosed due to few samples or the inability to perform immunocytochemistry.

In conclusion, the detection of bridges from endothelial cells is the pathognomonic feature of the diagnosis of HCC.

\section{References}

1. Islam T, Hossain F, Rumpa AP, Sikder NH, Bhuiyan MA Karim E and Hossain A: Ultrasound guided fine needle aspiration cytology: a sensitive diagnostic tool for diagnosis of intra-abdominal lesions. Bangladesh Med Res Counc Bull 1: 14-17, 2013.

2. Mueller M, Kratzer W, Oeztuerk S, Wilhelm M, Mason RA, Mao R and Haenle MM: Percutaneous ultrasonographically guided liver punctures: an analysis of 1961 patients over a period of ten years. BMC Gastroenterol 12: 173, 2012.

3. Crowe DR, Eloubeidi MA, Chhieng DC, Jhala NC, Jhala D and Eltoum IA: Fine-needle aspiration biopsy of hepatic lesions: computerized tomograpic-guided versus endoscopic ultrasoundguided FNA. Cancer 108: 180-185, 2006.

4. Balani S, Malik R, Malik R and Kapoor N: Cytomorphological variables of hepatic malignancies in fine needle aspiration smears with special reference to grading of hepatocellular carcinoma. J Cytol 2: 116-120, 2013.
5. Wee A: Fine needle aspiration biopsy of malignant mass lesions in the liver: a revisit of diagnostic profiles and challenges. J Gastrointest Oncol 1: 5-7, 2013.

6. Geier A, Gartung C, Staatz G, Nguyen HN and Matem S: Moderne diagnostik benigner und maligner raumforderungen der leber. Dtsch Ärztebl 47: A-3120/B-2647/C-2453, 2001 (In German).

7. Mrzljak A, Kardum-Skelin I, Cvrlje VC, Filipec-Kanizaj T, Sustercić D and Skegro D: Role of fine needle aspiration cytology in management of hepatocellular carcinoma: a single centre experience. Coll Antropol 34: 381-385, 2010.

8. Swamy MC, Arathi C and Kodandaswamy C: Value of ultrasonography-guided fine needle aspiration cytology in the investigative sequence of hepatic lesions with an emphasis on hepatocellular carcinoma. J Cytol 28: 178-184, 2011.

9. Khan S, Omar T and Michelow P: Effectiveness of the cell blocks technique in diagnostic cytopathology. J Cytol 3: 177-182, 2012.

10. Farkas S, Lang SA, Scherer M, Kirchner GI, Loss M and Schlitt HJ: Leberadenome: wann muss wirklich therapiert werden? Z Gastroenterol 49: 3-13, 2011 (In German).

11. Bioulac-Sage P, Laumonier H, Couchy G, Le Bail B, Sa Cunha A, Rullier A, Laurent C, Blanc JF, Cubel G, Trillaud H, Zucman-Rossi J, Balabaud C and Saric J: Hepatocellular adenoma management and phenotypic classification: the Bordeaux experience. Hepatology 50: 481-489, 2009.

12. Wilkens L, Flemming P, Gebel M, Bleck J, Terkamp C, Wingen L, Kreipe $\mathrm{H}$ and Schlegelberger B: Induction of aneuploidy by increasing chromosomal instability during differentiation of hepatocellular carcinoma. Proc Natl Acad Sci USA 101: 1309-1314, 2004

13. Edmondson HA and Steiner PE: Primary carcinoma of the liver: a study of 100 cases among 48,900 necropsies. Cancer 7: 462-504, 1954.

14. Dabbs DJ: Diagnostic immunohistochemistry. 2nd edition, 2006. 